\title{
Analysis of ripening-related gene expression in papaya using an Arabidopsis-based microarray
}

\author{
João Paulo Fabi', Graham B Seymour ${ }^{2}$, Neil S Graham², Martin R Broadley ${ }^{2}$, Sean T May ${ }^{2}$, Franco Maria Lajolo ${ }^{1,3}$, \\ Beatriz Rosana Cordenunsi ${ }^{1,3}$ and João Roberto Oliveira do Nascimento ${ }^{1,3^{*}}$
}

\begin{abstract}
Background: Papaya (Carica papaya L.) is a commercially important crop that produces climacteric fruits with a soft and sweet pulp that contain a wide range of health promoting phytochemicals. Despite its importance, little is known about transcriptional modifications during papaya fruit ripening and their control. In this study we report the analysis of ripe papaya transcriptome by using a cross-species (XSpecies) microarray technique based on the phylogenetic proximity between papaya and Arabidopsis thaliana.

Results: Papaya transcriptome analyses resulted in the identification of 414 ripening-related genes with some having their expression validated by $\mathrm{qPCR}$. The transcription profile was compared with that from ripening tomato and grape. There were many similarities between papaya and tomato especially with respect to the expression of genes encoding proteins involved in primary metabolism, regulation of transcription, biotic and abiotic stress and cell wall metabolism. XSpecies microarray data indicated that transcription factors (TFs) of the MADS-box, NAC and AP2/ERF gene families were involved in the control of papaya ripening and revealed that cell wall-related gene expression in papaya had similarities to the expression profiles seen in Arabidopsis during hypocotyl development.
\end{abstract}

Conclusion: The cross-species array experiment identified a ripening-related set of genes in papaya allowing the comparison of transcription control between papaya and other fruit bearing taxa during the ripening process.

Keywords: Oligo-chip, Heterologous microarray, Papaya ripening, Quantitative gene expression, Whole genome shotgun, Transcript profiling

\section{Background}

Papaya (Carica papaya L.) is an important crop cultivated in tropical and subtropical areas and the ripe fruit has a soft and sweet pulp with high amounts of provitamin A and antioxidants [1]. Papaya is a typical climacteric fruit, with striking colour changes, a rapid rise in ethylene production, and substantial pulp softening; it also responds to exogenous ethylene and 1-MCP applications $[2,3]$. The physico-chemical changes during papaya ripening are dependent on the expression of specific genes, and the identification of ripening-related genes involved in the activation of biochemical steps

\footnotetext{
* Correspondence: jronasci@usp.br

${ }^{1}$ University of São Paulo, Department of Food Science and Experimental Nutrition, FCF, São Paulo, Brazil

${ }^{3}$ University of São Paulo, - NAPAN - Food and Nutrition Research Center, São Paulo, Brazil

Full list of author information is available at the end of the article
}

relevant for fruit quality is of both scientific and commercial interest.

In order to understand the network of ripening genes in fleshy fruits, transcriptome studies are valuable tools. In the case of fruit such as tomato, microarrays have been used extensively $[4,5]$. However, for less well studied fruits, transcriptome analyses are based on thomemade' microarrays, such as the $\mu$ PEACH1.0 array [6], or classical transcript profiling by Differential Display-PCR or cDNA-AFLP [7-9]. With the development of highthroughput sequencing, several species have had their genome sequenced including the Hawaiian variety of papaya fruit [10]. Commercial oligo-chips are not currently available for these organisms and comprehensive RNA sequencing can still be costly often prohibiting routine experiments. However, a cross-species (XSpecies) microarray is an alternative approach that has been successfully used to study the transcriptomes of non-model organisms $[11,12]$.

\section{Biomed Central}

(c) 2012 Fabi et al.; licensee BioMed Central Ltd. This is an Open Access article distributed under the terms of the Creative Commons Attribution License (http://creativecommons.org/licenses/by/2.0), which permits unrestricted use, distribution, and reproduction in any medium, provided the original work is properly cited. 
Papaya is a member of family Caricaceae within the Brassicales, the same order as the 'model plant' Arabidopsis thaliana, which has been the object of many microarray experiments based on commercially available oligo-chips. Because the two species are relatively closely related, the use of Arabidopsis arrays to hybridize RNA from papaya should provide information on the transcriptome changes during ripening in papaya fruits.

In the present study we report the use of RNA from unripe and ripe papaya to probe the Affymetrix Arabidopsis GeneChip ATH1-121501 to profile ripeningrelated gene expression in papaya. The expression pattern of a number of genes likely to be related to fruit quality was validated by quantitative real-time PCR, and the data from papaya cross-species microarray was compared to microarray data from tomato (a climacteric fruit) and grape (a non-climacteric fruit). A comparative biology approach was then used to compare the putative proteins from papaya and protein sequences from Arabidopsis and other fleshy fruits in order to obtain information on the differences between these organisms in respect to evolutionary role in fruit ripening. The expression of transcription factors was divergent amongst three species, and XSpecies data indicated transcription factors (TFs) that may be involved in the control of papaya ripening. Comparison of the expression patterns of ripening-related TFs and down-stream effectors such as cell wall genes between papaya, fleshy fruits and Arabidopsis indicated both common and unique features in these higher regulatory networks governing ripening.

\section{Results}

Transcriptome characteristics of papaya fruit ripening: Use of XSpecies microarray

A probe-masking strategy utilising hybridization of papaya genomic DNA was used to identify probes with low or non-specific hybridization. The number of probe-pairs retained for analysis decreased rapidly (Additional file 1) as the DNA hybridization threshold was increased. In comparison the number of probesets reduced at a slower rate, which was consistent with the results obtained with other species $[11,12]$. The number of differentially expressed genes (fold change $>1.25, \mathrm{p}<0.05)$ was calculated at each threshold and the mask value of 75 returned the highest number of differentially expressed putative genes (414 probesets) (Additional file 2). The hierarchical clustering of the $\log _{2}$ values of these probe-sets intensities resulted in the discrimination of eight main clusters (Additional file 3) with different expression patterns. Clusters II, III, IV, V and VI, with 208 probe-sets, were up-regulated, while 205 probe-sets from clusters I, VII and VIII were down-regulated during ripening. Clusters I,
II and III was composed by genes with high levels of expression while clusters VI and VIII enclosed genes with the lowest levels of expression during papaya ripening. Clusters IV, V and VII enclosed genes with the highest differences in gene expression when $\log _{2}$ intensities were compared between unripe and ripe fruit.

Papaya probe-sets were separated into gene categories using the PageMan software and up-regulated probesets were organized according to the correspondent Arabidopsis Gene Ontology (Additional file 4) function (Figure 1). As was expected in a climacteric fruit, there were a wide range of genes up-regulated during fruit ripening, including those involved in primary metabolism (especially carbohydrate degradation) and energy transport and these findings are consistent with the high demand associated with ripening and the peak in $\mathrm{CO}_{2}$ production (as it was previously reported $[3,8]$ ) (Additional file 5). Genes encoding proteins involved in lipids, protein, and hormone metabolism, as well as cell signalling, signal transduction, and the response to biotic and abiotic stress were also up-regulated (Table 1).

\section{Comparative genomics of fruit ripening in papaya vs. Tomato and grape}

In order to visualize the probable cell functions altered in papaya and to compare them to those of another climacteric fruit (tomato) and a non-climacteric fruit (grape), the bins of differentially expressed probe-sets for papaya (fold change $>1.25, \mathrm{p}<0.10$; Additional file 6 ), tomato and grape (fold change $>2.0$, authors' statistical cut-off) were run using the MapMan software [13]. The aim was identify sets of expression profiles that might be conserved between or unique to climacteric and nonclimacteric fruit. Data chosen for analysis focused on the main changes associated with the ripening process, such as the comparison between red and mature green tomato and post-véraison and pre-vérasion grape.

Figure 2 shows a schematic Venn diagram of upregulated probe-sets from papaya XSpecies, tomato and grape microarrays obtained from MapMan analysis (Additional file 7). Despite differences between climacteric and non-climacteric ripening, the proportion of upregulated genes varied amongst species, with a similar number of over-expressed genes between ripe papaya and grapes.

A schematic overview of ripening regulation and some of its cellular responses (Figure 3) showed a high proportion of up-regulated transcription factors (TFs) in papaya (61\%) (Additional file 8). When probe-sets from papaya experiments were analysed in terms of GO molecular function (Additional file 4), 103 probe-sets (25\%) accounted for genes responsible for nucleotides and nucleic acids binding, translation initiation factors and 
A
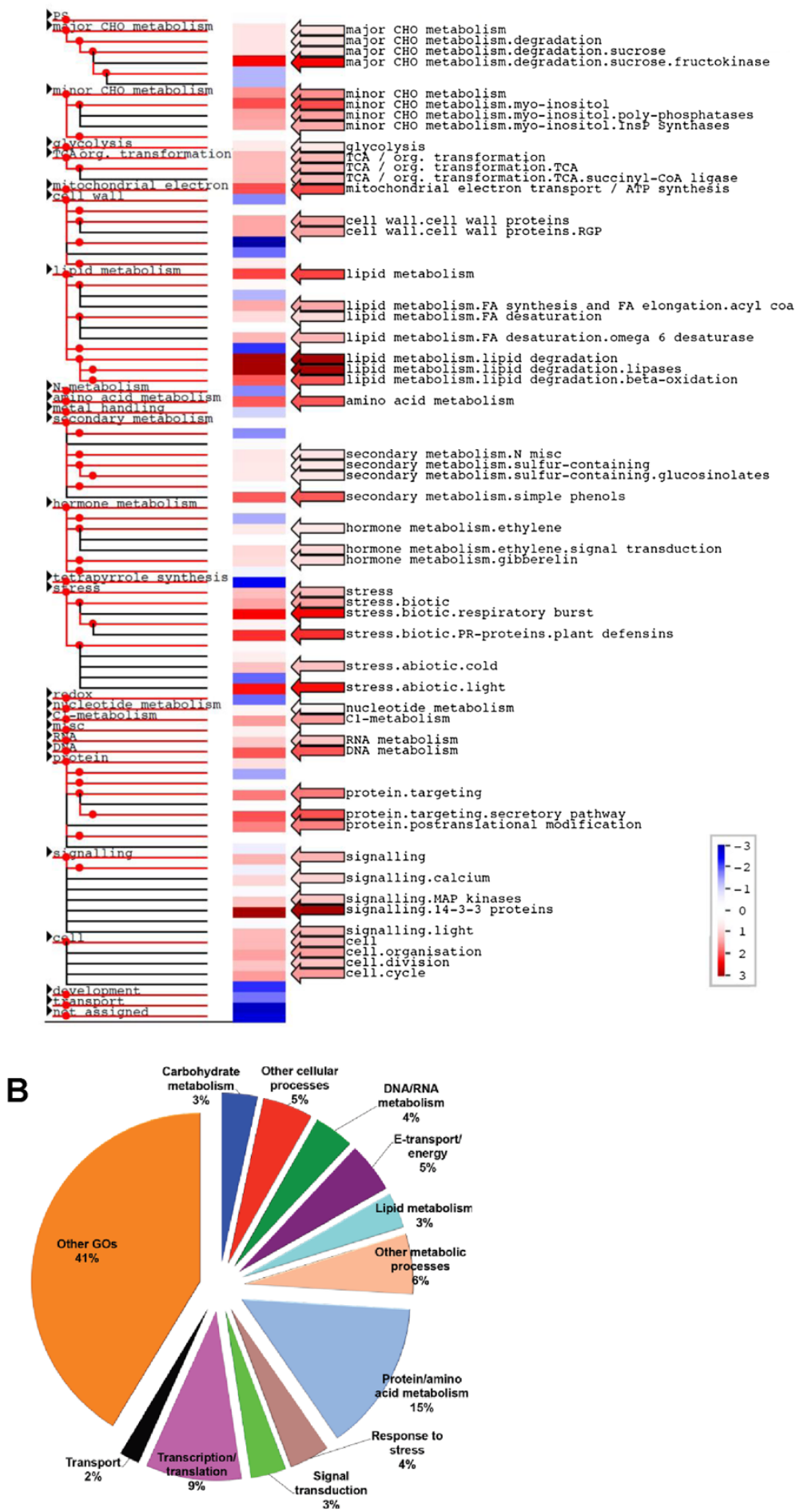

Figure 1 The ripening papaya transcriptome was studied using the cross-species microarray technique and the Affymetrix ATH1-

121501 GeneChip from A. thaliana. A) Papaya normalized gene expression values were subjected to an analysis to identify overrepresented functional categories using PageMan (indicated by arrows and names). Gene expression data are presented as $\log _{2}$ fold changes in comparison with the unripe fruit. The data were subjected to a Wilcoxon test, and the results are displayed in false-color code. Red colored bins are significantly up-regulated, whereas blue colored bins are significantly down-regulated $(p<0.05)$. All non-significant categories and some downregulated bins are collapsed in the display. B) Pie chart showing the percentage of genes in ripe papaya that are over represented with respect to each of the GO biological processes. 
Table 1 Differentially expressed probe-sets identified in papaya fruit

TAIR annotation

Gene description (annotated by GO analysis)

Carbohydrate Metabolism

AT1G50390

AT3G08900

AT2G22240

AT2G40220

AT3G26380

AT5G66280

AT1G75940

AT2G06850

AT4G28320

\section{E-transport/Energy}

AT5G51060

AT3G24200

AT2G29990

AT2G05180

AT5G08300

AT2G36530

AT3G56840

AT5G53460

\section{Lipid Metabolism}

AT3G62590

AT1G53920

AT5G65110

AT1G30370

AT4G30950

AT3G15850

AT1G28590

Protein/Amino Acid Metabolism

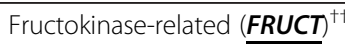

Reversibly glycosylatable polypeptide-related

Myo-inositol 1-phosphate synthase

Abscisic acid-insensitive 4 (AB/4) identical to AP2 domain transcription factor

Glycosyl hydrolase family 27 (alpha-galactosidase/melibiase) ( $\underline{\boldsymbol{A}-\mathbf{G A L}}$

GDP-D-mannose 4,6-dehydratase 1 (GMD1)

Glycosyl hydrolase family 1 (beta-glucosidase)

Xyloglucan endotransglycosylase (ext/EXGT-A1) $\underline{\underline{\boldsymbol{X T H}}})$

Glycosyl hydrolase family 5/cellulase ((1-4)-beta-mannan endohydrolase) (CELL)

\begin{tabular}{|c|c|}
\hline $\log _{2}$ Fold $^{+}$ & $P$-value \\
\hline 1.738 & 0.0358 \\
\hline 0.759 & 0.0323 \\
\hline 0.748 & 0.0414 \\
\hline 0.361 & 0.0472 \\
\hline-0.342 & 0.0216 \\
\hline-0.386 & 0.0349 \\
\hline-0.482 & 0.0402 \\
\hline-0.862 & 0.0498 \\
\hline-2.911 & 0.0228 \\
\hline 1.809 & 0.0189 \\
\hline 1.610 & 0.0234 \\
\hline 1.108 & 0.0128 \\
\hline 0.834 & 0.0275 \\
\hline 0.708 & 0.0194 \\
\hline 0.523 & 0.0400 \\
\hline-0.593 & 0.0458 \\
\hline-0.744 & 0.0452 \\
\hline 3.851 & 0.0367 \\
\hline 1.710 & 0.0157 \\
\hline 1.038 & 0.0070 \\
\hline 0.972 & 0.0296 \\
\hline 0.725 & 0.0393 \\
\hline 0.344 & 0.0204 \\
\hline-0.364 & 0.0373 \\
\hline
\end{tabular}

Protein/Amino Acid Metabolism

\begin{tabular}{llrl}
\hline AT5G63860 & UVB-resistance protein UVR8 & 1.625 & 1.080 \\
\hline AT1G76700 & DnaJ protein family (DnaJ1) & 0.674 & 0.0340 \\
\hline AT1G14570 & UBX domain-containing protein & 0.0262 \\
\hline AT1G16030 & Heat shock protein 70b $\underline{\text { HSP70) }}$ & 0.669 & 0.544 \\
\hline AT4G17830 & Aminoacylase similar to acetylornithine deacetylase & 0.0053 \\
\hline AT4G23600 & Aminotransferase similar to nicotianamine aminotransferase & 0.534 \\
\hline AT1G17720 & Type 2A protein serine/threonine phosphatase & 0.420 & 0.0491 \\
\hline AT4G00690 & Ulp1 protease similar to SUMO-1/Smt3-specific isopeptidase 2 & 0.0292 \\
\hline AT5G20890 & Chaperonin & -0.427 & 0.0443 \\
\hline AT4G20850 & Tripeptidyl-peptidase II & -0.438 & 0.0102 \\
\hline AT3G58640 & Protein Kinase Family Protein & -0.474 & 0.0280 \\
\hline AT5G65940 & 3-hydroxyisobutyryl-coenzyme A hydrolase (CoA-thioester hydrolase) & -0.599 & 0.0207 \\
\hline AT5G22060 & DnaJ protein family (DnaJ3) & -0.711 & 0.0376 \\
\hline Response to Stress/Defense & -1.032 \\
\hline AT2G43510 & Trypsin inhibitor-related & 0.0416 \\
\hline AT3G22840 & Early light-induced protein & 1.401 & \\
\hline AT3G17020 & Expressed protein similar to ER6 protein & 0.0030 \\
\hline
\end{tabular}


Table 1 Differentially expressed probe-sets identified in papaya fruit (Continued)

\begin{tabular}{|c|c|c|c|}
\hline AT5G47100 & Calcineurin B-like protein 9 (CBL9) & 0.385 & 0.0326 \\
\hline AT3G16450 & Jacalin lectin family similar to myrosinase-binding protein homolog & -0.402 & 0.0039 \\
\hline AT1G72950 & Disease resistance protein & -0.565 & 0.0447 \\
\hline AT2G17310 & F-box protein family & -1.211 & 0.0150 \\
\hline AT3G03670 & Peroxidase & -1.831 & 0.0497 \\
\hline \multicolumn{4}{|c|}{ Signal Transduction } \\
\hline AT2G30420 & Myb family transcription factor & 1.689 & 0.0456 \\
\hline AT2G24500 & $\mathrm{C} 2 \mathrm{H} 2$-type zinc finger protein -related & 0.856 & 0.0103 \\
\hline AT3G61950 & bHLH protein family & 0.589 & 0.0216 \\
\hline AT2G06020 & Myb family transcription factor & -1.482 & 0.0367 \\
\hline \multicolumn{4}{|c|}{ Transcription/Translation } \\
\hline AT3G61830 & Auxin response factor-related protein $18 \underline{(\boldsymbol{A R F 1 8})}$ & 1.004 & 0.0247 \\
\hline AT3G55620 & Eukaryotic translation initiation factor 6 (EIF-6) & 0.743 & 0.0050 \\
\hline AT1G15360 & AP2/ERF transcription factor 2 (ERF2) & 0.596 & 0.0407 \\
\hline AT4G11160 & Translation initiation factor IF-2 (Basic helix-loop-helix family protein) & 0.579 & 0.0272 \\
\hline AT5G60910 & MADS-box protein (AGL8) & 0.462 & 0.0135 \\
\hline AT3G24050 & GATA transcription factor 1 & 0.364 & 0.0307 \\
\hline AT5G06950 & bZIP transcription factor & -0.327 & 0.0262 \\
\hline AT3G05860 & MADS-box protein & -0.357 & 0.0030 \\
\hline AT1G05180 & Auxin-resistance protein 1 ( $\underline{\boldsymbol{A X R} \mathbf{1})}$ & -0.472 & 0.0230 \\
\hline AT1G46768 & AP2 domain protein RAP2.1 ( & -0.730 & 0.0492 \\
\hline AT1G58110 & bZIP family transcription factor & -1.311 & 0.0243 \\
\hline \multicolumn{4}{|l|}{ Transport } \\
\hline AT4G18290 & Inward rectifying potassium channel (KAT2) & 1.868 & 0.0166 \\
\hline AT5G59030 & Copper transport protein & 1.015 & 0.0171 \\
\hline AT3G05165 & Sugar transporter & -0.711 & 0.0453 \\
\hline AT3G12390 & Nascent polypeptide associated complex alpha chain & -0.801 & 0.0182 \\
\hline AT1G77990 & Sulfate transporter -related & -1.269 & 0.0347 \\
\hline \multicolumn{4}{|l|}{ Other GOs } \\
\hline AT5G06650 & Zinc finger-related protein (GO: trichome differentiation) & 3.432 & 0.0429 \\
\hline AT5G16050 & 14-3-3 protein GF14 upsilon (grf5) (GO: unknown) & 1.466 & 0.0369 \\
\hline AT5G65430 & 14-3-3 protein GF14 kappa (grf8) (GO: unknown) & 1.450 & 0.0370 \\
\hline AT5G01190 & Laccase (diphenol oxidase) (GO: lignin catabolic process) & 1.024 & 0.0060 \\
\hline AT3G08900 & Reversibly Glycosylated Polypeptide 3) (GO: cellulose biosynthetic process) & 0.759 & 0.0323 \\
\hline AT3G12290 & Tetrahydrofolate dehydrogenase (GO: folic acid biosynthesis) & 0.778 & 0.0222 \\
\hline AT1G70140 & Formin homology 2 (FH2) domain-containing protein (GO: cell tip growth) & 0.760 & 0.0241 \\
\hline AT5G66170 & Senescence-associated protein (GO: aging) & 0.742 & 0.0069 \\
\hline AT5G07200 & Gibberellin 20-oxidase (GO: gibberellin biosynthetic process) & 0.578 & 0.0156 \\
\hline AT1G73690 & Cell division protein kinase (GO: regulation of cell cycle) & 0.506 & 0.0341 \\
\hline AT5G67160 & Hydroxycinnamoyl/benzoyltransferase-related protein (GO: unknown) & 0.504 & 0.0467 \\
\hline AT5G48450 & Pectinesterase (pectin methylesterase) (PME1) (GO: cell tip growth) & 0.501 & 0.0479 \\
\hline AT1G04130 & Tetratricopeptide Repeat (TPR)-containing Protein (GO: unknown) & -0.347 & 0.0496 \\
\hline AT1G67700 & Auxin-regulated protein $(\underline{\boldsymbol{A R P}})$ (GO: unknown) & -0.396 & 0.0364 \\
\hline AT4G12420 & Pectinesterase (pectin methylesterase) ( $\underline{P M E 2})$ (GO: cell tip growth) & -0.421 & 0.0226 \\
\hline AT5G45360 & F-box protein similar to SKP1 interacting partner 2 (SKIP2) (GO: unknown) & -0.448 & 0.0406 \\
\hline AT2G39700 & Expansin putative (EXP) (GO: cell wall organization and biogenisis) & -0.474 & 0.0128 \\
\hline
\end{tabular}


Table 1 Differentially expressed probe-sets identified in papaya fruit (Continued)

\begin{tabular}{lllr}
\hline AT2G39750 & Early-responsive to dehydration stress protein (ERD3) (GO: unknown) & -0.642 & 0.0294 \\
\hline AT4G04340 & Early-responsive to dehydration stress protein (ERD4) (GO: unknown) & -0.749 & 0.0256 \\
\hline AT2G38700 & Mevalonate diphosphate decarboxylase $(\boldsymbol{M E V})$ (GO: isoprenoid biosynthesis) & -0.793 & 0.0224 \\
\hline AT4G24780 & Pectate lyase family 1 ( $\boldsymbol{P L})$ (GO: cell wall organization and biogenesis) & -1.228 & 0.0408 \\
\hline
\end{tabular}

${ }^{\dagger} \log 2$ of average signal value ripe divided by average signal value unripe.

${ }^{+\dagger}$ Names of the genes analyzed by qPCR-Real Time.

ribosomes constituents. Table 2 shows the main upregulated TFs in the three species regarding the three different ripening experiments.

The cellular response to ripening in these three fruits was also different, especially to biotic and abiotic stress and redox regulation (Figure 3 ). While tomato responses were the increase of genes related to abiotic stress and decrease of those related to biotic stress, grape responded in an opposite way (Table 3). Nonetheless, papaya responded to ripening in a similar way to tomato, with abiotic genes being expressed in the same time course than tomato ones.

\section{Validation of gene expression and comparative biology between papaya and fleshy fruit organs}

In order to validate the XSpecies experiment, the expression of 21 probe-sets that were satisfactory aligned to

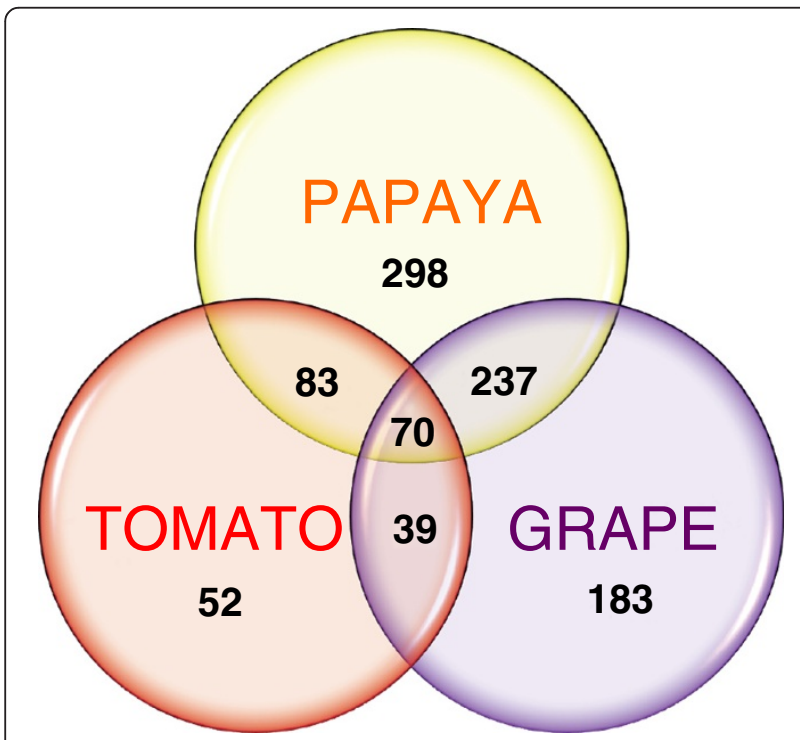

Figure 2 Venn diagram representing the distribution of papaya, tomato and grape up-regulated genes obtained from microarray data. Numbers within circles show the number of exclusive up-regulated genes and numbers within intersections show common up-regulated genes. A threshold value of 0.3 was used to construct the diagram based on $\log _{2}$ fold values. It was possible to group 962 genes from 1091 genes from papaya (> 1.25 fold), 1144 genes from tomato (> 2.00 fold) and 1150 genes from grape (> 2.00 fold). Tomato microarray data was downloaded from http://ted.bti.cornell.edu (Ozaki et al., 2010); grape microarray data was downloaded from http://biomedcentral.com (Pilati et al., 2007).
Arabidopsis genes were analysed by qPCR throughout papaya ripening. Papaya genes were named according to the Arabidopsis functions and grouped together, as shown in Figure 4. Quantitative analysis revealed $A$ GAL, EXP, FRUCT, LIP3, ACX, ARP, ENOL, HSP70 and $E R F 2$ were induced during ripening, while $A R F 18, C E L L$, MEV, LIP, PME1, PME2, PL, RAP2, XET, ERD3, ERD4 and $A X R$ were decreased during ripening. Contrasting results between $\mathrm{qPCR}$ and XSpecies experiments were observed for three genes (ARF18, EXP and PME1).

Comparative analysis of the translated amino acids sequences for all genes analysed from qPCR experiments indicated some papaya putative proteins were more similar to those from species with fleshy fruits than to the Arabidopsis ones (Figure 5). In general, proteins from primary and secondary metabolism (FRUCT, LIP, $M E V$ ) and transcription factors (ERF2, ARF18, AXR1, $A R P$ ) appeared to be phylogenetically closer to those from species with fleshy fruits, whereas abiotic stress (ERD3, ERD4) and cell wall metabolism (A-GAL, PL, PME1, PME2, CELL, XTH) proteins are more closely related to those from Arabidopsis. Contrasting results were observed for proteins with high degree of conservation, such as ENOL, RAP2, HSP, ACX and PL, where homology was determined primarily by non-conserved regions and less by conserved domains. Because cell wall related genes shared greater homology with Arabidopsis, a comparison of gene expression in ripe papayas was conducted using a published Arabidopsis microarray study of gene expression in 5 or 11-day-old hypocotyls (ratio 11-day/5-day) [14]. These data (Table 4) also indicate that this set of genes had comparable gene expression levels and might act on cell wall polymers in a similar way.

\section{Discussion}

In this study we investigated the transcriptome of ripening papaya $[7,8]$ using fruits at two contrasting physiological stages and the Affymetrix ATH1-121501 GeneChip for Arabidopsis in an XSpecies microarray [11]. The number of differentially expressed probe-sets was consistent with the results obtained with other species $[11,12]$ but was fewer than those from regular microarray experiments, especially with regarding comparative analyses between unripe and ripe fruits $[15,16]$. Although XSpecies results have less power than a 


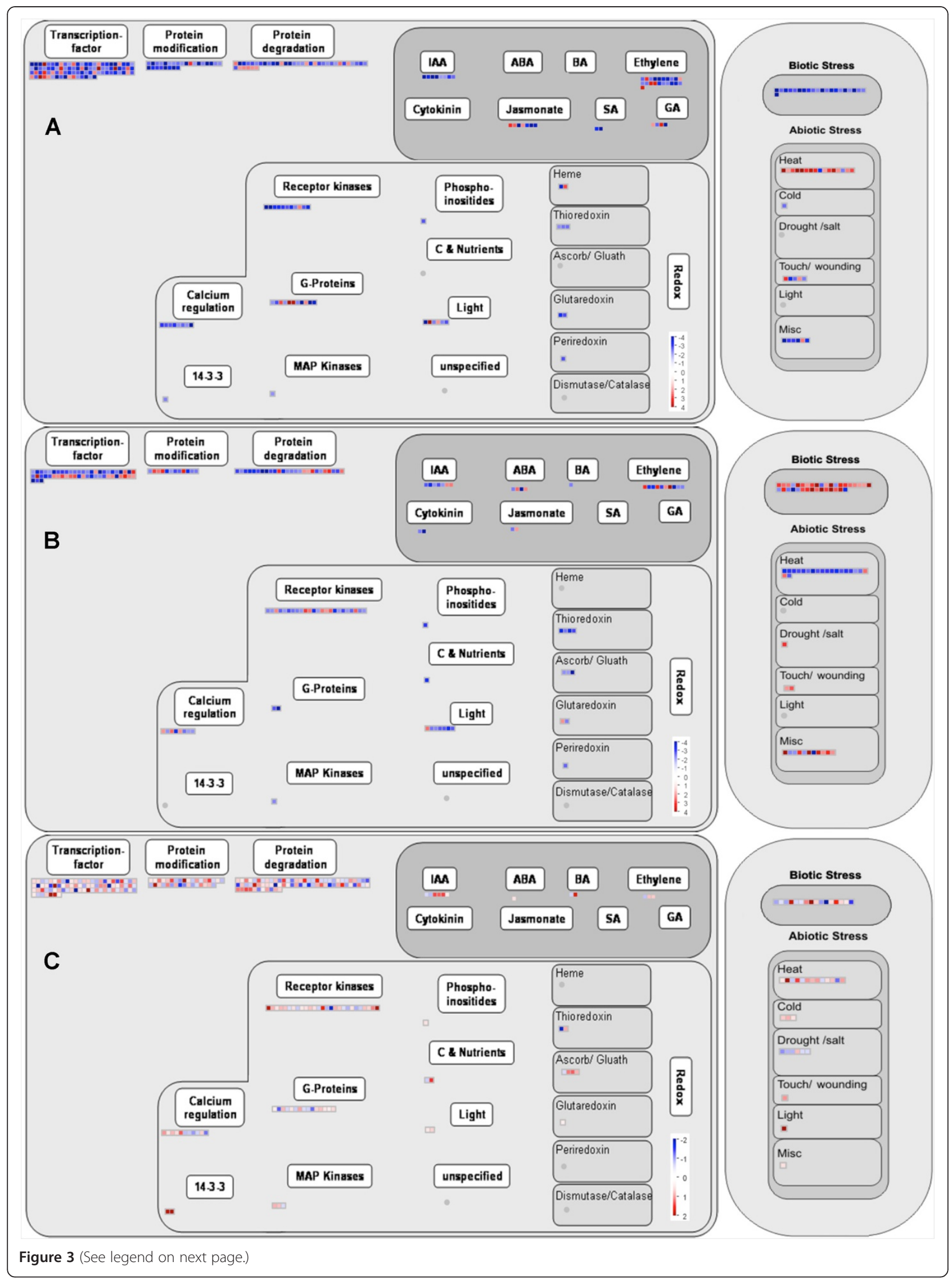


(See figure on previous page.)

Figure 3 Overview of ripening regulation and cellular responses to ripening from tomato, grape and papaya. Transcripts from tomato (A), grape (B) and papaya $(\mathbf{C})$ fruits were analysed using the MapMan software uploaded with microarrays results. Blue and red represent a decrease and an increase of expression respectively, relative to unripe fruits. It is visible 244 transcripts (from 1144 ) for tomato (> 2.00 fold), 171 transcripts (from 1150) for grape (> 2.00 fold) and 276 transcripts (from 1091) for papaya (> 1.25 fold). Tomato microarray data was downloaded from http://ted.bti.cornell.edu (Ozaki et al., 2010); grape microarray data was downloaded from http://biomedcentral.com (Pilati et al., 2007).

regular microarray experiment and technologies such as RNAseq performed by Next Generation Sequencing (NGS), the technique was able to identify important genes related to metabolic processes involved in papaya ripening. Surprisingly, despite papaya and Arabidopsis being members of the order Brassicales, only cell wallrelated genes shared a greater homology among the genes studied. This may reflect shared metabolic pathways which differ from other fleshy fruit. Fleshy fruits showed greater homology between transcription factors which might indicate shared transcriptional regulatory networks.

\section{Deduced roles of ripening-related genes in papaya Primary metabolism}

The high energy demand at climacteric ripening was evidenced by the up-regulation of genes related to Krebs and TCA cycles (AT5G08300, AT2G29990, AT3G24200 and AT5G51060), cytochromes (AT2G05180, AT5G06900, AT1G01280), and hexose metabolism (AT2G36530 and AT1G50390). Similarly, genes involved in lipid metabolism, were also affected. These included cell membrane lipases (AT3G62590, AT1G53920 and AT1G28590), and up-regulation of genes responsible for the synthesis of unsaturated fatty acids (AT4G30950 and AT3G15850). Down-regulation of the $M E V$ gene (AT2G38700) suggests the main precursors for volatiles production and carotenoid biosynthesis could be produced by the MEP pathway inside the plastids during papaya ripening [17]. Fabi et al. [8] identified another transcript related to $M E V$ gene, suggesting mevalonate accumulation prior ripening.

\section{Transcriptional regulation}

When the probe-sets were analysed in terms of GO molecular function (Additional file 4), a high number of genes responsible for nucleotide and nucleic acid binding, translation initiation and ribosomes constituents were observed, indicating control of ripening at both the level of transcription and translation. Five members of the $M Y B$ family, which is important for ripening since $M Y B$ genes are known to regulate secondary metabolism and colour accumulation [18], were differentially expressed during ripening. Since colour of papaya pulp is correlated with accumulation of carotenoids [3], papaya $M Y B$ TFs might show distinct role in other metabolism during ripening.
Three closely-related ERF/AP2 genes had diverse expression throughout papaya ripening, with an $A P 2$ gene (AT4G39780) and an ERF gene (AT1G15360) being up-regulated (Table 2). While some genes from AP2/ERF family are related to improving Arabidopsis resistance to abiotic stress [19], others have been shown to be responsible for controlling tomato ripening [20,21]. Specific APETALA2 genes (so called SlAP2a to SlAP2e genes) are expressed throughout normal tomato ripening and SlAP $2 a$ gene may balance the activities of positive ripening regulators as a negative feedback loop. Moreover, a previous study showed an APETALA2 gene subclade IIIc (COLD BIND FACTOR II gene) is involved in regulation of apple pulp softening during cold storage and/or ethylene treatment [22]. In fact, papaya ERF2 and RAP2 putative proteins share higher similarity to diverse APETALA2 proteins from apples and tomato (Figure 6) rather than the SIAP2a protein from tomato.

Three genes members of auxin signalling pathway (ARF18, AXR1 and $A R P$ ), a hormone that impairs ripening [6], were identified in our experiments. Whereas $A R P$ was the only up regulated gene during ripening, $A R F 18$ was phylogenetically close to SLARF family, the auxin response factors from S. lycopersicum (Figure 5). These data suggest that ripening in papaya involves auxin signalling, in common with other fruits $[23,24]$.

Many different TFs are involved in control of ripening in fleshy fruits. In tomato, master regulators include MADS-box (SEP4-like, RIN, TDR4, TAG1, TAGL1), $S B P$-box (CNR), HB-box (LeHB-1) and NAC genes [25]. Strawberry ripening involves a SEP1/2-like gene (FaMADS9) [26], and for banana a SEP3-like gene (MaMADS2) [27]. In bilberry, accumulation of anthocyanins is controlled by an SQUAMOSA-class MADSbox TF VmTDR4, orthologous to the TDR4 gene in tomato [28]. Papaya shows range of TFs which are homologous to these master regulators and show ripeningrelated changes in gene expression (Table 2). Despite each species seeming to have specific sets of ripeningrelated transcription factors, their exact functions in papaya fruits remain to be elucidated.

\section{Cell wall-related genes}

Papaya pulp softening shows a remarkable change during ripening, and this is thought to be due to the activities of cell wall hydrolases [29]. Seven 
Table 2 Differentially expressed transcription factors from papaya, tomato and grape

\begin{tabular}{|c|c|c|c|c|c|}
\hline \multirow[t]{2}{*}{ Gene description } & \multirow{2}{*}{$\begin{array}{c}\text { TAIR } \\
\text { annotation }\end{array}$} & \multicolumn{3}{|c|}{$\log _{2}$ Fold $^{\dagger}$} & \multirow[t]{2}{*}{ Probe Set ID } \\
\hline & & Papaya & Tomato $^{\dagger \dagger}$ & Grape $^{t+\dagger}$ & \\
\hline AP2 domain protein RAP2.1 ( & AT1G46768 & -0.73 & & & 245807_at \\
\hline AP2 domain-containing protein & AT5G52020 & - & 4.15 & - & lesaffx.63544.1.s1_at \\
\hline AP2 domain-containing transcription factor & AT4G39780 & 0.54 & - & - & 252859_at \\
\hline AP2/ERF transcription factor & AT2G47520 & - & 2.18 & - & les.4102.1.s1_at \\
\hline AP2/ERF transcription factor 2 (ERF2) & AT1G15360 & 0.60 & - & - & 262595_at \\
\hline ATHB23 (A. thaliana HOMEOBOX PROTEIN 23) & AT1G26960 & 0.41 & - & - & 263690_at \\
\hline Auxin response factor-related protein 18 (ARF18) & AT3G61830 & 1.00 & - & - & 251289_at \\
\hline Basic helix-loop-helix (bHLH) family protein & AT2G34820 & 0.55 & - & - & 267426_at \\
\hline Basic helix-loop-helix (bHLH) family protein & AT3G61950 & 0.59 & - & - & 251299_at \\
\hline Basic helix-loop-helix (bHLH) family protein & AT4G09180 & - & 2.20 & - & lesaffx.19952.1.s1_at \\
\hline BLH7 (BELL 1-LIKE HOMEODOMAIN 7) & AT2G16400 & 1.76 & - & - & 263557_at \\
\hline $\mathrm{C} 2 \mathrm{H} 2$-type zinc finger protein -related & AT2G24500 & 0.86 & - & - & 265662_at \\
\hline Embryo-abundant protein-related & AT2G41380 & - & - & 3.26 & 1620276_at \\
\hline Eukaryotic translation initiation factor 6 (EIF-6) & AT3G55620 & 0.74 & - & - & 251776_at \\
\hline GATA transcription factor 1 & AT3G24050 & 0.36 & - & - & 256916_at \\
\hline KNAT3 (KNOTTED1-LIKE HOMEOBOX GENE 3) & AT5G25220 & - & 2.45 & - & lesaffx.67017.1.s1_at \\
\hline MADS-box protein - Floral homeotic protein PISTILLATA (PI) & $N M^{*}$ & - & - & 3.02 & 1614123_at \\
\hline MADS-box protein (AGL20) & AT2G45660 & - & - & 2.53 & 1612908_at \\
\hline MADS-box protein (AGL8) & AT5G60910 & 0.46 & - & - & 247553_at \\
\hline MADS-box protein (AGL8) - TDR4 transcription factor & AT5G60910 & - & 1.38 & - & les.4461.1.S1_s_at \\
\hline MADS-box transcription factor (AGL2 - MADS-RIN) & AT5G15800 & - & 3.97 & - & les.4450.1.s1_at \\
\hline MYB family transcription factor & AT2G30420 & 1.69 & - & - & 267495_at \\
\hline MYB family transcription factor & AT5G08520 & 0.83 & - & - & 250524_at \\
\hline MYB family transcription factor & AT5G45420 & 0.80 & - & - & 248954_at \\
\hline MYB10 (myb domain protein 10) & AT3G12820 & 0.72 & - & - & 257689_at \\
\hline MYB111 (myb domain protein 111) & AT3G46130 & - & 2.58 & - & les.4982.1.s1_at \\
\hline MYB19 (myb domain protein 19) & AT5G52260 & 0.39 & - & - & 248343_at \\
\hline MYB21 (myb domain protein 21) & AT3G27810 & - & 5.75 & - & lesaffx.70738.1.a1_at \\
\hline MYB43 (myb domain protein 43) & AT5G16600 & - & 2.66 & - & lesaffx.64717.1.a1_at \\
\hline MYB73 (myb domain protein 73) & AT4G37260 & 0.34 & - & - & 246253_at \\
\hline MYB75 (myb domain protein 75) - PRODUCTION OF ANTHOCYANIN PIGMENT 1 & NM & - & - & 3.74 & 1620959_s_at \\
\hline MYB95 (myb domain protein 95) & AT1G74430 & 0.46 & - & - & 260237_at \\
\hline MYR1 (MYB-RELATED PROTEIN 1) & AT3G04030 & 0.43 & - & - & 258807_at \\
\hline NAC domain protein (NAC13) & AT1G32870 & 0.79 & - & - & 261192_at \\
\hline NAC domain protein (NAC4) & NM & - & - & 2.05 & 1610466_at \\
\hline NAC domain protein (NAC42) & AT2G43000 & - & 1.30 & - & lesAffx.66359.1.S1_at \\
\hline NAC domain protein (NAC47) & AT3G04070 & - & - & 2.20 & 1607620_at \\
\hline Zinc finger ( $\mathrm{C} 2 \mathrm{H} 2$ type) family protein & AT1G68130 & - & - & 2.07 & 1613842_at \\
\hline Zinc finger ( $\mathrm{C} 2 \mathrm{H} 2$ type) family protein & AT5G66730 & 1.07 & - & - & 247054_at \\
\hline
\end{tabular}

${ }^{\dagger} \log _{2}$ of average signal value ripe divided by average signal value unripe;

${ }^{+t}$ Microarray data downloaded from http://ted.bti.cornell.edu (Ozaki et al., 2010);

${ }^{+t+}$ Microarray data downloaded from http://biomedcentral.com (Pilati et al., 2007);

* NM: no match with TAIR sequences. 
Table 3 Differentially expressed probe-sets related to cellular response to ripening

\begin{tabular}{|c|c|c|c|c|c|}
\hline \multirow[t]{2}{*}{ Gene Description } & \multirow{2}{*}{$\begin{array}{c}\text { TAIR } \\
\text { annotation }\end{array}$} & \multicolumn{3}{|c|}{$\log _{2}$ Fold $^{+}$} & \multirow[t]{2}{*}{ Probe set ID } \\
\hline & & Papaya & Tomato $^{+\dagger}$ & Grape $^{++\dagger}$ & \\
\hline \multicolumn{6}{|l|}{ Biotic stress } \\
\hline Acidic endochitinase (CHIB1) & AT5G24090 & & -2.98 & & les.435.1.s1_at \\
\hline Acidic endochitinase (CHIB1) & AT5G24090 & & & 2.84 & 1612050_at \\
\hline ATEP3 (Arabidopsis thaliana chitinase class $M$ ) & AT3G54420 & & -5.52 & & lesaffx.69659.1.s1_at \\
\hline ATLP-1 (Arabidopsis thaumatin-like protein 1) & AT1G18250 & & -2.57 & & lesaffx.66226.2.s1_at \\
\hline Chitinase, putative & AT2G43580 & -0.50 & & & 260561_at \\
\hline Defensin-like (DEFL) family protein & AT5G43510 & -1.08 & & & 249157_at \\
\hline Disease resistance family protein / LRR family protein & AT3G23010 & 0.37 & & & 257764_at \\
\hline Disease resistance protein (CC-NBS-LRR class) & AT1G12290 & 1.22 & & & 259534_at \\
\hline Disease resistance protein (TIR-NBS-LRR class) & AT5G44510 & 0.47 & & & 249058_at \\
\hline Glyco_hydro_19 chitinase & AT2G34690 & & & 2.76 & 1620505_at \\
\hline LCR70 (Low-molecular-weight cysteine-rich 70) & AT2G02120 & 0.86 & & & 266141_at \\
\hline Pathogenesis-related protein & AT4G33720 & & -2.22 & & les.4693.1.s1_at \\
\hline Pathogenesis-related thaumatin family protei & AT1G20030 & -0.71 & & & 261248_at \\
\hline Polygalacturonase inhibiting protein 1 (PGIP1) & AT3G23170 & & & 2.07 & 1613339_at \\
\hline RHD2 (ROOT HAIR DEFECTIVE 2) & AT5G51060 & & -2.35 & & les.335.1.s1_at \\
\hline RHD2 (ROOT HAIR DEFECTIVE 2) & AT5G51060 & 1.80 & & & 248486_at \\
\hline Thaumatin-like protein & AT1G77700 & & & 2.76 & 1607225_at \\
\hline Thaumatin-like protein & AT1G75030 & & & 2.31 & 1616617_at \\
\hline \multicolumn{6}{|l|}{ Abiotic stress } \\
\hline 15.7 kDa class I-related small heat shock protein-like & AT5G37670 & & 2.03 & & lesaffx.70264.1.s1_at \\
\hline $18.1 \mathrm{kDa}$ class I heat shock protein (HSP18.1) & AT3G23170 & & & -2.46 & 1612385_at \\
\hline DNAJ heat shock family protein & AT2G22360 & -0.49 & & & 264002_at \\
\hline DNAJ heat shock N-terminal domain-containing protein & AT1G56300 & & 2.15 & & lesaffx.68054.1.s1_at \\
\hline DNAJ heat shock N-terminal domain-containing protein & AT2G42750 & & & -2.92 & 1609580_at \\
\hline DNAJ heat shock N-terminal domain-containing protein & AT3G58020 & -0.56 & & & 251618_at \\
\hline DNAJ heat shock N-terminal domain-containing protein & AT1G76700 & 1.08 & & & 259876_at \\
\hline HSC70-1 (heat shock cognate 70 kDa protein 1) & AT1G74310 & & & -2.70 & 1621357_s_at \\
\hline HSP101 (heat shock protein 101) & AT1G74310 & & & -2.70 & 1615503_at \\
\hline HSP18.2 (HEAT SHOCK PROTEIN 18.2) & AT5G59720 & 0.66 & & & 247691_at \\
\hline HSP20-like chaperone & AT3G22530 & 1.68 & & & 256934_at \\
\hline HSP70 (heat shock 70 kDa protein) & AT2G32120 & 0.75 & & & 265675_at \\
\hline HSP70 (heat shock protein 70) & AT3G12580 & & 2.00 & & lesaffx.10807.1.s1_at \\
\hline HSP81-1 (heat shock protein 81-1) & AT5G52640 & & 2.90 & & les.3134.1.s1_at \\
\hline \multicolumn{6}{|l|}{ Redox (ascorbate and glutathione) } \\
\hline Glutathione peroxidase & $N M^{*}$ & & & -4.84 & 1614945_a_at \\
\hline L-ascorbate peroxidase & AT4G09010 & & & -2.12 & 1618209_at \\
\hline L-galactose dehydrogenase (L-GalDH) & AT4G33670 & 0.66 & & & 253307_at \\
\hline Monodehydroascorbate reductase & AT3G09940 & 0.87 & & & 258941_at \\
\hline
\end{tabular}

\footnotetext{
${ }^{\dagger} \log _{2}$ of average signal value ripe divided by average signal value unripe.

${ }^{+\dagger}$ Microarray data downloaded from http://ted.bti.cornell.edu (Ozaki et al., 2010).

${ }^{+t+}$ Microarray data downloaded from http://biomedcentral.com (Pilati et al., 2007).

* NM: no match with TAIR sequences.
} 


\section{PRIMARY METABOLISM}
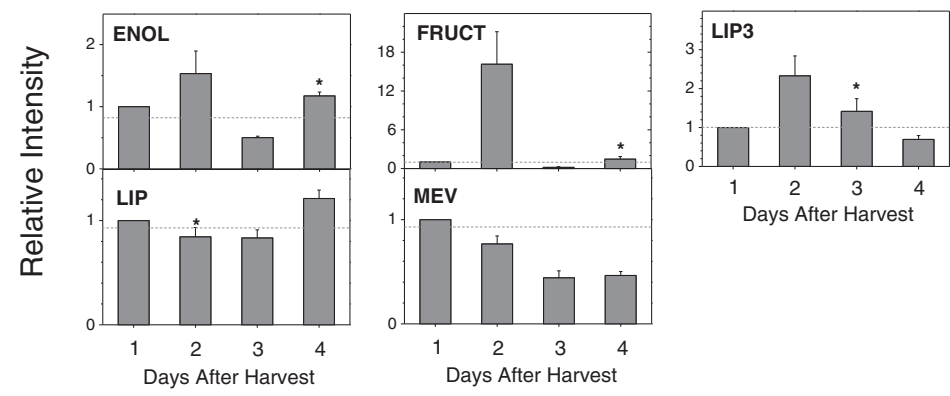

TRANSCRIPTIONAL REGULATION
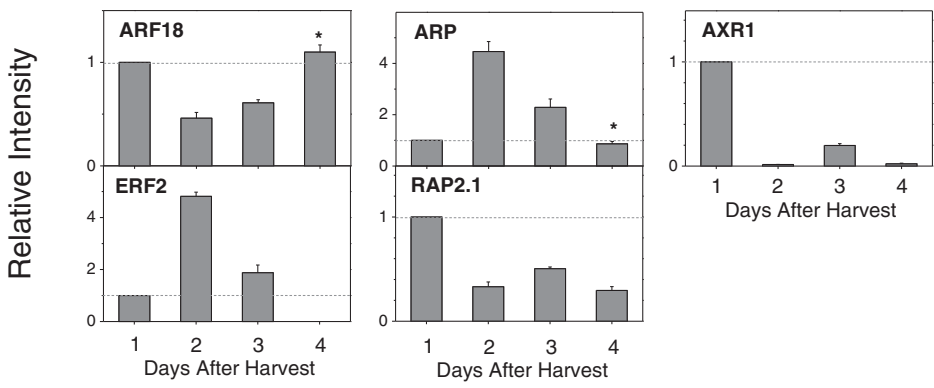

CELL WALL-RELATED GENES
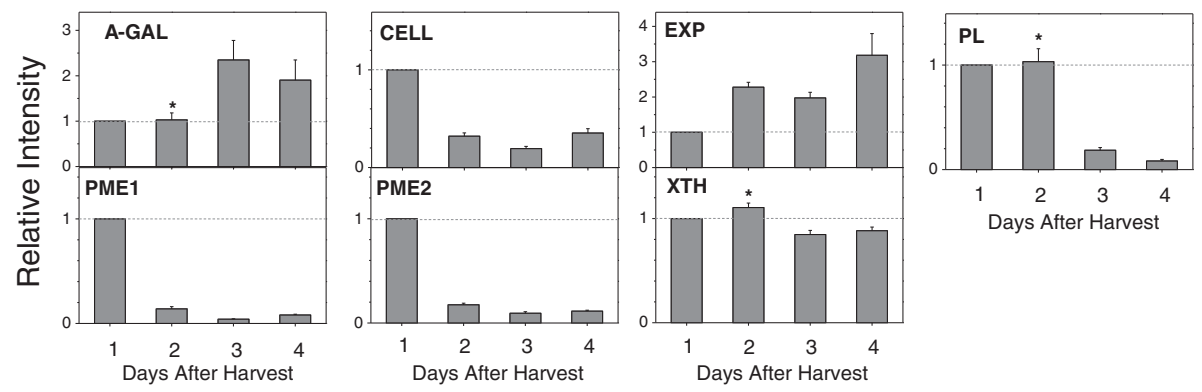

RESPONSE TO STRESS AND PLANT DEFENCE
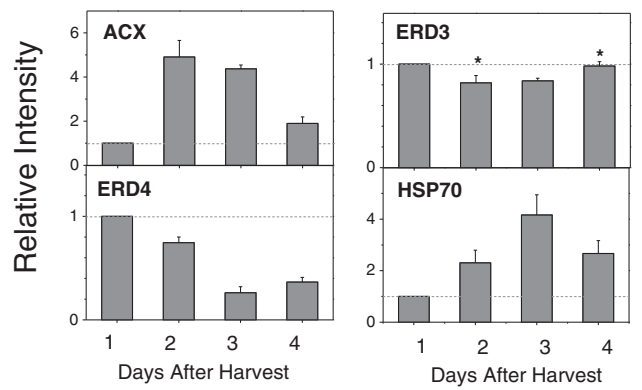

Figure 4 QPCR validation of papaya ripening-related gene expression. Real-time PCR was used to analyse the expression patterns of putative genes during papaya ripening with days after harvest. Column height indicates relative mRNA abundance; expression values in unripe fruit at the first day after harvest were set to 1. All data were normalised to the actin and 185 expression levels. Error bars on each column indicate SDs from four technical replicates. Asterisks represent samples that were not significantly different compared to the first day after harvest using one-way ANOVA and the Tukey test $(a<0.05, n=4)$. Different boxes represent each issue pointed in the Discussion (Primary metabolism, Transcriptional regulation, Cell wall-related genes, Response to stress and plant defence). 


\section{PRIMARY METABOLISM}

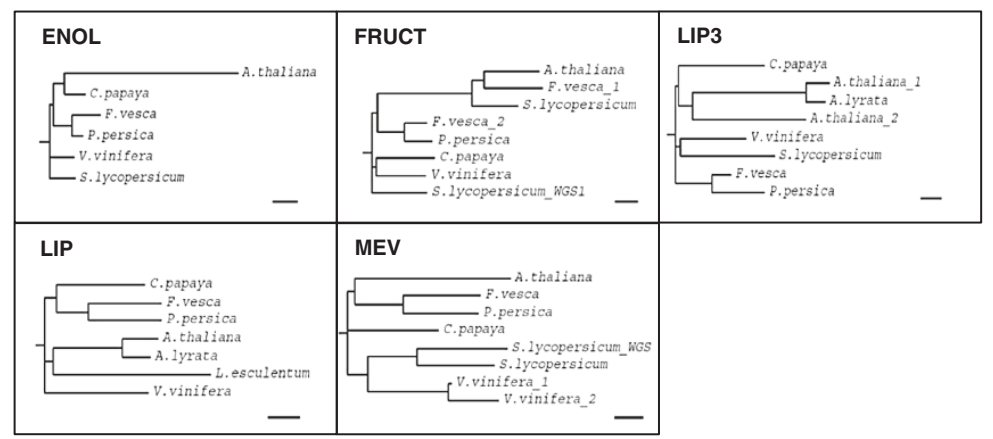

TRANSCRIPTIONAL REGULATION

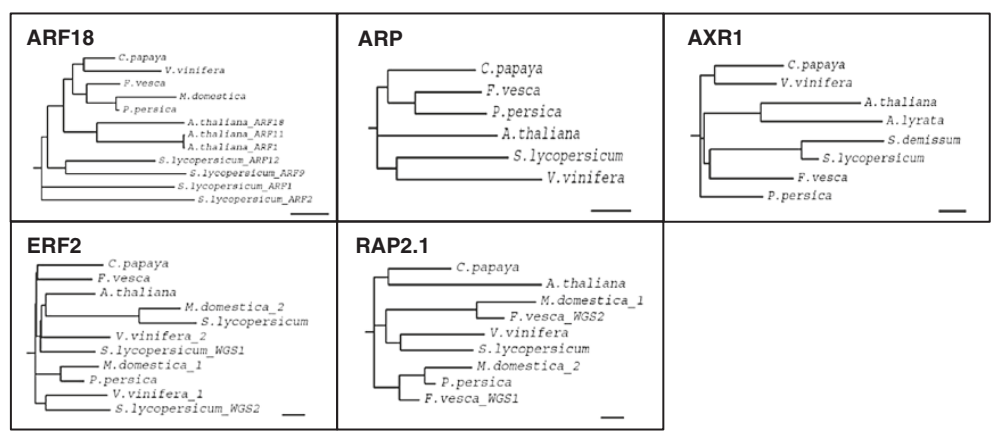

CELL WALL-RELATED GENES

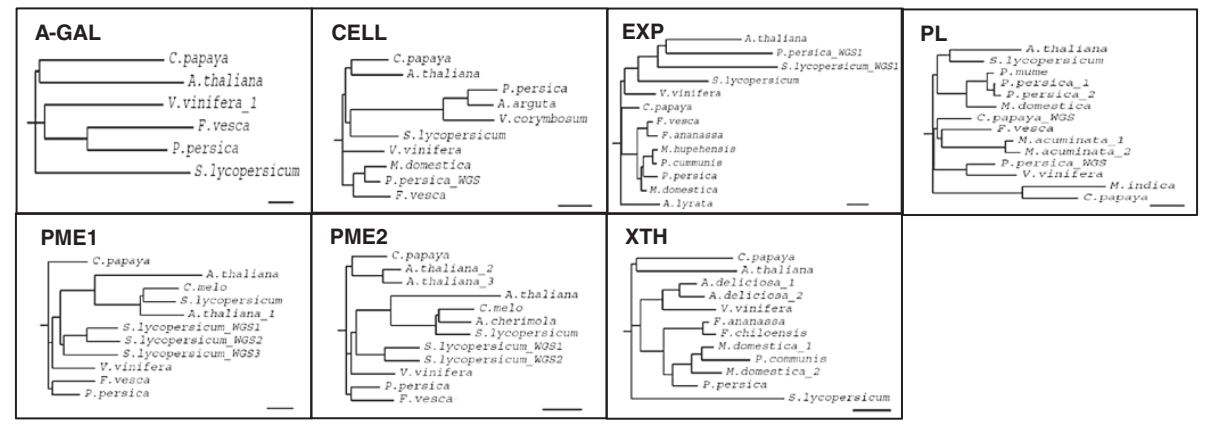

RESPONSE TO STRESS AND PLANT DEFENCE

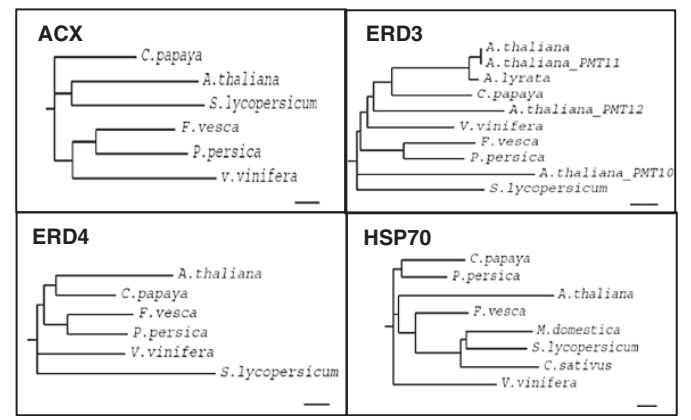

Figure 5 Unrooted phylograms encompassing putative proteins from papaya, $A$. thaliana and several fleshy fruit organs. Phylogenetic trees were calculated using Neighbor Joining method based on the ClustalW alignment of deduced amino acids sequences. Branch length values are based on the scale bar meaning 0.1 residue substitutions per site. Different boxes represent each issue pointed in the Discussion (Primary metabolism, Transcriptional regulation, Cell wall-related genes, Response to stress and plant defence). 
Table 4 Cell wall-related genes from ripe papaya and $A$. thaliana hypocotyl

\begin{tabular}{|c|c|c|c|c|}
\hline \multirow[t]{2}{*}{ Gene Description } & \multirow{2}{*}{$\begin{array}{c}\text { TAIR } \\
\text { annotation }\end{array}$} & \multicolumn{2}{|c|}{$\log _{2}$ Fold $^{+}$} & \multirow{2}{*}{$\begin{array}{l}\text { Probe } \\
\text { set ID }\end{array}$} \\
\hline & & Papaya & A. thaliana $^{\dagger \dagger}$ & \\
\hline Pectate lyase $(P L)$ & AT1G09910 & -1.01 & -0.06 & 264658_at \\
\hline Expansin A15 (EXPA15) & AT2G03090 & -0.42 & -0.01 & 266770_at \\
\hline Xyloglucan endotransglycosylase (ext/EXGT-A1) (XTH) & AT2G06850 & -0.86 & -0.65 & 266215_at \\
\hline UDP-glucuronate 4-epimerase (GAE6) & AT3G23820 & -1.55 & -0.52 & 256865_at \\
\hline Cellulose synthase-like 12 (CSL12) & AT4G07960 & 0.34 & -0.07 & 255175_at \\
\hline Pectinesterase (pectin methyl esterase) (PME2) & AT4G12420 & -0.42 & -0.27 & 254815_at \\
\hline Pectate lyase family $1(P L)$ & AT4G24780 & -1.23 & 0.67 & 254119_at \\
\hline Cellulose synthase-like 9 (CSL9) & AT5G03760 & -0.6 & -0.64 & 250892_at \\
\hline COBRA-like gene 4 (COBL4) & AT5G15630 & 0.66 & -0.47 & 246512_at \\
\hline Pectinesterase (pectin methylesterase) (PMEI) & AT5G48450 & $0.5(-3.42)^{*}$ & -0.36 & 248704_at \\
\hline Arabinogalactan protein 22 (AGP22) & AT5G53250 & 1.13 & 0.96 & 248252_at \\
\hline GDP-mannose 4,6-dehydratase 1 (GMD1) & AT5G66280 & -0.42 & -0.24 & 247094_at \\
\hline
\end{tabular}

${ }^{\dagger} \log _{2}$ of average signal value ripe vs. unripe for papaya and $\log _{2}$ of average signal value 11-day-old hypocotyls vs. 5 days for $A$. thaliana.

${ }^{++}$Microarray data downloaded from www.biomedcentral.com/content/supplementary/1471-2164-10-505-s1.pdf (Jamet et al. 2009).

${ }^{+t+}$ Number represented by qPCR analysis.

putative cell wall-related genes were differentially expressed: four related to pectin hydrolysis $(\alpha$-galactosidase - AT3G26380; pectate lyase - AT4G24780; pectin methylesterases - AT5G48450 and AT4G12420), two related to cellulose hydrolysis and rearrangement (cellulase - AT4G28320; xyloglucan endotransglycosylase AT2G06850) and one related to cell expansion (expansin - AT2G39700). Mostly genes related to PGs and expansin were up-regulated while those related to PMEs, PLs and glucosidases were down-regulated.

The up-regulation of an $\alpha$-galactosidase gene $(A-G A L)$ observed in our experiments is consistent with previous data reported by Soh et al. [30] and Nogueira et al. [31] on ripening of papaya fruit. On the other hand, changes in pectate lyases $(P L)$ were detected, but the reduced levels contrast with the expected role of the enzyme during ripening. In other fruits, such as bananas [32] and mangoes [33] $P L$ is thought to contribute to the pectin disassembly that leads to the pulp softening of ripe fruits. Pectin methylesterases were also apparently down-regulated during ripening. Solubilisation of pectin in ripe papayas may be governed principally by the action of polygalacturonases on previously de-esterified pectin chains $[29,34]$ in addition to the action of $\alpha$-galactosidases. Cellulose and hemicellulose processing in the papaya pulp could not be inferred from our results, since the genes related to hydrolysis and rearrangements of cellulose (cellulase and xyloglucan endotransglycosylase, respectively) were down-regulated during papaya ripening, in contrast to the up-regulation in ripe tomato and strawberry [35,36]; respectively). Gaete-Eastman et al. [37] observed expansin gene expression was upregulated during ripening in mountain papaya and it was inversely correlated to pulp texture. This pattern of expression is in agreement with the expansin gene from 'Golden' papaya (Figure 7). Papaya EXP is related to the gene products encoded by FaEXP4, PcEXP5 and PpEXP2 from strawberry, pear and peach, respectively [38-40]; Figure 6). All of these genes are up-regulated during fruit ripening, suggesting conservation of gene action in the softening of a range of fleshy fruits species. However in some instances cell wall changes in papaya resembled events in non-fruit tissues. An Arabidopsis microarray study [14] investigating gene expression during 5 or 11day-old hypocotyls (ratio 11-day/5-day) showed a transcription profile, at least for some of the cell wall-related genes, that was highly similar to that found in ripening papaya (Table 4). This reveals interesting characteristics of cell wall remodelling which may have evolved from the same ancestral Brassicales.

\section{Response to stress and plant defence}

No representative differences in expression of probe-sets related to 'response to stress' (six probe-sets up-regulated and six probe-sets down-regulated) were observed, and only two out of six 'plant defence response' probesets were up-regulated. However, genes from other GO classes may be considered based on their putative functions. Acyl-CoA oxidases $(A C X s)$ are members of lipid metabolism' GO, and have a key role in the jasmonic acid (JA) biosynthesis, an important compound in protection against pathogens and insects [41]. The upregulated papaya $A C X$ gene could contribute to the defence system during ripening, since it showed a 5-fold increase in transcript abundance. Papaya ACX protein shared high similarity with that from tomato, where a peroxisomal ACX protein is critical for the $\beta$-oxidation through JA biosynthesis and systemic wound signalling, 


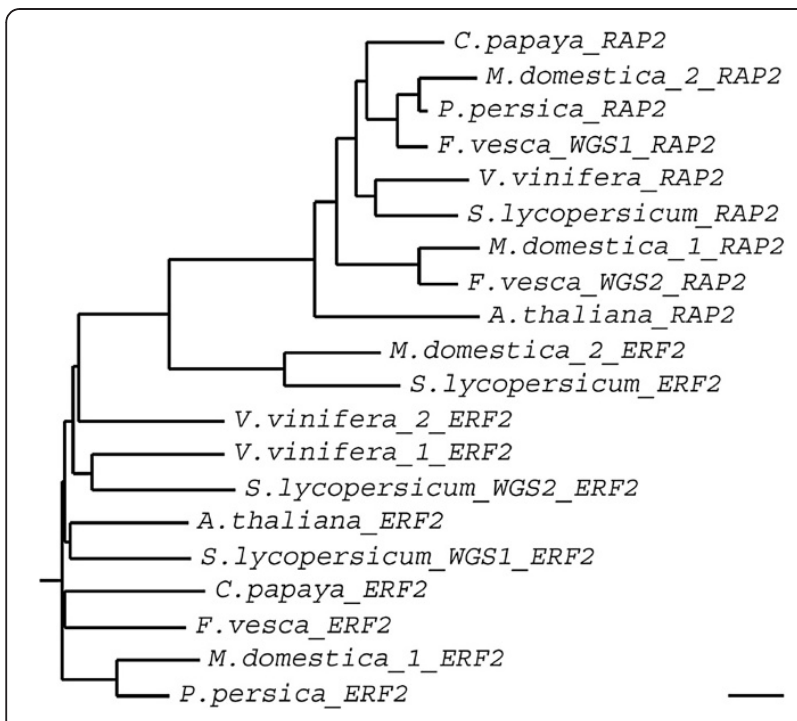

Figure 6 Unrooted phylogram encompassing putative RAP2 and ERF2 proteins from papaya, $A$. thaliana and various other fleshy fruits. The phylogenetic tree was calculated using Neighbor Joining method based on the ClustalW alignment of deduced amino acids sequences. Branch length values are based on the scale bar meaning 0.1 residue substitutions per site. TFs protein sequences from RAP2 are: C. papaya (ABIM01006309), A. thaliana (ABD57516), M. domestica_1 (ADE41138), M. domestica_2 (ADE41135), V. vinifera (XP_002284933), S. lycopersicum (AEKE02013217), F. vesca (WGS_1: AEMH01010803; WGS_2: AEMH01014087), P. persica (AEKV01002084). TFs protein sequences from ERF2 are: C. papaya (ABIM01003643), A. thaliana (BAC42579), M. domestica_1 (ADE41128), M. domestica_2 (ADE41114), V. vinifera ([1]: CBI28202; [2]: CBI36313), S. lycopersicum (AAL75809; WGS_1: AEKE02002405; WGS_2: AEKE02023116), F. vesca (AEMH01012502), P. persica (AEKW01000994).

indicating this gene might also be responsible for JA biosynthesis in papaya [42]. Two putative papaya ERD3 and ERD4 genes (AT2G39750 and AT4G04340, respectively) were down-regulated. These proteins are methyltransferases that respond positively to abiotic stresses such as cold treatment and prolonged mild osmotic stress [43].

Analysis of the papaya transcriptome reveals that like tomato there is overexpression of heat-shock protein (HSPs) genes. Heat-shock proteins can work as chaperones in protein folding; under stress conditions they can re-establish normal protein conformation [44] and degrade damaged or misfolded peptides [45]. Genes normally associated with response to abiotic stress are often seen expressed in ripening fruits $[8,46]$.

Chitinases and thaumatins were over-expressed in grapes, conferring plant protection against saprophytic organisms [47], but down-regulated in tomato instead [15], none of these genes were differentially expressed in papaya. Only some genes related to protein inhibition and those of so-called leucine repeat proteins (LRRs), which are very important in defence against pathogenic fungi [48] were induced. Regarding redox regulation,

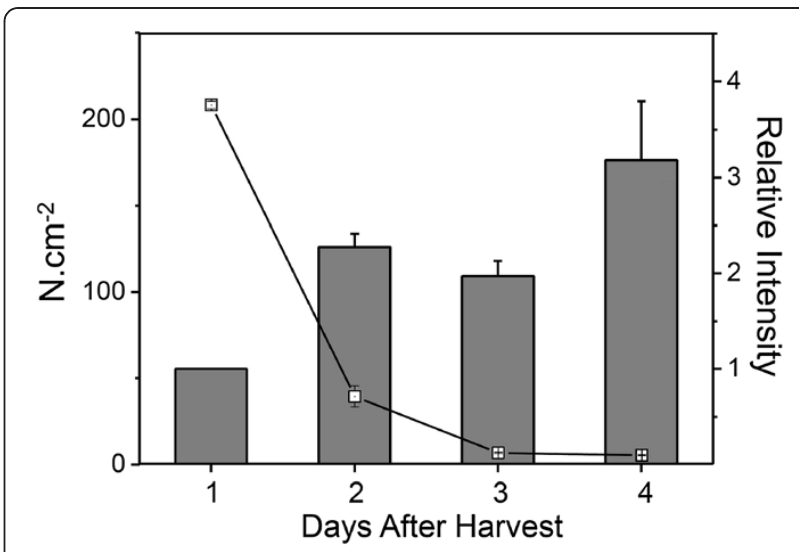

Figure 7 Correlation between pulp softening and expansin gene expression (EXP - AT2G39700) during papaya ripening. Pulp firmness (Open squares) was monitored through the ripening process by a texturometer (Fabi et al., 2007) and measures are given by $\mathrm{N} . \mathrm{cm}^{-2}$. The mRNA abundance of expansin gene is indicated by column height. Expression values in unripe fruit at the first day after harvest were set to 1. Error bars indicate SDs of the mean ( $n=12$ for papaya texture analysis and $n=4$ for $\mathrm{QPCR}$ analysis).

ascorbic acid (Vitamin C) accumulates in these three fruits [49-51], but only papaya cross-species microarray revealed genes related to ascorbic acid biosynthesis: the up regulated monodehydroascorbate reductase and an L-galactose dehydrogenase genes.

\section{Conclusions}

The heterologous hybridization microarray was successfully applied in the study of transcripts changes associated to papaya fruit, a commercially relevant crop from a non-model organism. The ripening of papaya represents a time-course of cellular metabolism changes, characterized by differential expression of numerous genes involved in primary metabolism, hormonal signalling, transcriptional regulation, abiotic stress and cell wall metabolism. Among the genes identified are transcription factors (TFs) of the MADS-box, NAC and $A P 2 / E R F$ gene families, which are master regulators in other fruits indicating conservation of function for ripening control genes across different taxa. Moreover, data revealed cell wall-related gene expression was more similar to Arabidopsis hypocotyl development profiles than those from other fleshy fruit perhaps revealing characteristics of cell wall remodelling mechanisms specific to the Brassicales.

The phylogenetic relationship between transcription factors of fleshy fruits might indicate shared transcriptional regulatory networks. Although data presented in the manuscript is not enough to indicate how climacteric and non-climacteric fruits evolved, and some genes specific to papaya or those specifically expressed in fleshy organs might have been overlooked with the 
heterologous microarray, other approaches, e.g. RNAseq, are likely to contribute to new perspectives on how different fleshy fruits respond to ripening.

\section{Methods \\ Samples}

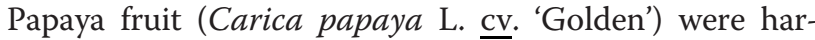
vested at colour break to $1 / 4$ yellow (around 150 days after anthesis). One replicate of each unripe and ripe fruit samples for microarray assay was obtained from a previous study in 2007 [3]. The other two replicates of unripe and ripe samples for microarray and also for quantitative PCR analyses were obtained in 2010. Soon after harvest, the initial respiration and ethylene levels were determined [3]. Each experimental sample (unripe papaya and successive time points during the ripening process) comprised 12 individual fruits. After removal of the peel and seeds, the sliced pulp of each fruit was frozen in liquid $\mathrm{N}_{2}$ and stored at $-80^{\circ} \mathrm{C}$.

\section{Genomic DNA and total RNA extractions}

Genomic DNA and total RNA extraction protocols were the same as previously described [29]. Total RNA was purified using the "RNeasy ${ }^{\circledR}$ Kit" (Qiagen). Nucleic acids were quantified in the NanoDrop ${ }^{\circledR}$ ND-1000 (Nanodrop Technologies ${ }^{\odot}$ ) and gel analyzed to verify their integrity [52]. Total RNA were also analyzed with Agilent 2100 Bioanalyser" (Agilent Technologies ${ }^{\odot}$ ) to confirm its integrity before each hybridization.

\section{Genomic DNA hybridization, probe-selection and cRNA hybridization}

Genomic DNA was labelled with the Bioprime DNA labelling System kit (Invitrogen ${ }^{\mathrm{Tm}}$ ), hybridized with Affymetrix GeneChip ATH1-121501 (Affymetrix) for 16 hours at $45^{\circ} \mathrm{C}$ using standard hybridization protocols (Affymetrix $\left.^{(}\right)$and analyzed by computed scanning. Using a perl script [53] and a range of user-defined threshold values (from 0 to 500), chip definition files (CDF) were created with papaya genomic DNA hybridization data (mask files). Probe-pairs were retained for analysis if their signal values were greater than the defined threshold. Probe-sets were retained if they contained more than one probe-pair. Total RNA (5 $\mu$ g) from papaya pulp was reverse-transcribed to generate first strand cDNA containing a 5'-T7 RNA polymerase promoter sequence. Double stranded cDNA was synthesized using standard protocol, and the resulting samples were in-vitro transcribed by T7 DNA polymerase using biotinylated nucleotides to generate complementary RNAs (cRNAs). Purified cRNA $(15 \mu \mathrm{g})$ were heat-fragmented and hybridized to ATH1-121501 for 16 hours at $45^{\circ} \mathrm{C}$. The complete protocol has already been published [11]. For each fruit stage (unripe and ripe), a triplicate of hybridization was undertaken and all the hybridizations have been submitted to GEO (http://www.ncbi.nlm.nih. gov/geo; accession number GSE38105).

\section{Data analyses}

Microarray Analysis Suite (MAS Version 5.0; Affymetrix) was used to generate .CEL files for each RNA hybridization. These files were loaded into GeneSpring version 7.2 (Agilent Technologies) software using the Robust Multichip Average (RMA) pre-normalization algorithm [54]. The computer files that were being loaded in GeneSpring were filtered using the CDF files generated using the genomic DNA hybridization. For each replicate array, each probe-set signal value from ripe samples was compared to the probe-set signal value of unripe samples to give gene expression ratios. Differentially expressed genes were identified using one-way ANOVA with a Benjamini and Hochberg false discovery rate multiple testing correction. The differentially expressed genes had their $\log _{2}$ signal intensities computed from the replicate chips and hierarchical clustering was carried out using the EPCLUST software [55] with a complete linkage algorithm and the Euclidian distance on normalized vectors of length 1 (chord distance) as parameters.

\section{Comparative analyses using PageMan and MapMan}

Normalized gene expression data were subjected to analysis of functional categories using PageMan and MapMan functional categories [56,57]. Using the Wilcoxon test it was possible to assume whether significantly more genes in ripe vs. unripe point were upregulated when normalized to their average expression. Expression data ( $\log _{2}$ fold) from papaya microarray (ripe X unripe) was loaded and analysed in MapMan software for visualization of the cellular pathway [13] against Arabidopsis mapping (Ath_AFFY_ATH1_TAIR8_Jan2010). In the same way, expression data ( $\log _{2}$ fold) from Solanum lycopersicum cultivar MicroTom (ripe X mature green; [58]) and Vitis vinifera cv. Pinot Noir (post-veráison X pre-véraison; [59]) were loaded and analysed in MapMan software, using data from Ozaki et al. [15] against S. lycopersicum mapping (Slyc_AFFY_SGN_BUILD2_070709) and Pilati et al. [14] against $V$. vinifera mapping (Vvin_AFFY_09), respectively. $\log _{2}$ fold values of differentially expressed probe-sets from three species were compared and a Venn diagram enclosing only the $\log _{2}$ values, not the probe-set IDs (since three different platforms were used) was created. For papaya up-regulated probe-sets, the Arabidopsis gene annotations and functional classifications were analysed using the gene ontology (GO) function of the GeneSpring software. 


\section{Quantitative analysis of gene expression by real time-PCR ( $q P C R)$}

For the validation of putative papaya genes identified by the XSpecies hybridization, the Arabidopsis genes represented in the hybridized chips were aligned individually against the WGS database using the BLASTN tool (score $\geq 100$ and e-value $\leq 1 \mathrm{e}^{-30}$ as cut-off values). Papaya putative coding sequences that were satisfactory aligned to Arabidopsis genes were evaluated following the 'Minimum Information for Publication of Quantitative Real-Time PCR Experiments - MIQE' [60] and also according to the parameters: (1) pair of primers with melting temperature of $60^{\circ} \mathrm{C}$ and absence of primersdimers and hairpins; (2) amplicon size between 75 and 200 bp; (3) amplicon evaluation with the mfold program [61]; and (4) amplicon alignment with an unique papaya WGS sequence (in order to not amplify two closelyrelated genes or a duplicated one). Twenty-one putative genes satisfied the above mentioned criteria and had their expression levels quantified. Primers were designed using Primer 3 (v.0.4.0) tool [62], and the sequences are shown in Additional file 9. As an internal controls, the putative actin gene located on chromosome LG9 contig 1059 (GenBank accession no. ABIM01001059) was used with sense (5'-CGT GAC CTT ACT GAT CAC TTG-3') and reverse (5'-GTC AAG GGC AAT GTA AGA CAG3') primers in combination with the $18 \mathrm{~S}$ rRNA (GenBank accession no. U42514) with sense (5'-AAA CGG CTA CCA CAT CCA AG-3') reverse (5'-CGA AGA GCC CGG TAT TGT TAG GG-3') primers. After oncolumn digestion of DNA with DNase RNase-free $\left(\right.$ NucleoSpin $^{\circledR}$ - Macherey $\mathrm{Nagel}^{\odot}$ ), first-strand cDNA was synthesized with random primers from $1 \mu \mathrm{g}$ total RNA using the ImProm-II Reverse Transcription System (Promega). For primer testing and identity confirmation, the fragments from preliminary PCR were cloned and sequenced. Real-time PCR was performed using the Platinum SYBR Green qPCR Supermix UDG (Invitrogen) in a "Rotor-Gene 3000 four channel Multiplexing System" (Corbett Research). The amplification was carried out under the following conditions; $50^{\circ} \mathrm{C}$ for $2 \mathrm{~min}$ followed by an initial denaturation step at $95^{\circ} \mathrm{C}$ for $2 \mathrm{~min}, 40$ cycles at $95^{\circ} \mathrm{C}$ for $15 \mathrm{~s}, 60^{\circ} \mathrm{C}$ for $30 \mathrm{~s}$, and $72^{\circ} \mathrm{C}$ for $30 \mathrm{~s}$. Non Template Controls (NTCs) and melting curve analyses of amplicons were analysed for all experiments. The threshold cycle $(\mathrm{Ct})$ values of the four technical replicate reactions were averaged using the Rotor-Gene 3000 software and quantification was performed using the relative standard curve method [63]. Samples used in $q P C R$ experiments were a mixture of, at least, 32 fruits from 2010 second and third biological replicates [8] (Additional file 5). Developmental parameters included ripening-related events such as $\mathrm{CO}_{2}$ and ethylene production as well as pulp softening [3]. The results of the standard curves calculation are in Additional file 10. Data were analysed against the first day after harvest by one-way ANOVA, and means were compared using the Tukey test at $\alpha<0.05$. Statistical analysis was carried out using OriginPro version 8 (OriginLab ${ }^{\circledR}$ ).

\section{Comparative biology analysis between fleshy fruit organisms}

In order to identify genes similarities shared between some fleshy fruit organs, a comparative biology analysis was done using qPCR tested papaya genes. The validated probe-sets were aligned to WGS database of papaya genome and the putative corresponding proteins were identified. Sequential TBlastN analyses were done using the putative papaya proteins and the WGS database for fleshy fruit organisms such as tomato (S. lycopersicum), strawberry ( $F$. vesca), peach ( $P$. persica) and grape $(V$. vinifera), and the corresponding proteins were also obtained for each organism. If otherwise stated, all sequences were identified from this manner. Together with Arabidopsis proteins and some other proteins, they were aligned using ClustalW [64] and phylogenetic trees were drawn using the Phylodendron ${ }^{\odot}$ software [65]. The Genbank ID and sequences of proteins used in comparative biology analysis are in Additional file 11.

\section{Additional files}

\begin{abstract}
Additional file 1: Effect of Carica papaya genomic DNA (gDNA) hybridization on probe-pairs and probe-sets from the ATH1-121501 chip. This additional figure describes how different values of hybridization intensity threshold (masks) affect the probe-sets and probe-pairs retained after papaya genomic hybridization in A.thaliana commercial chip.

Additional file 2: Differentially expressed probe-sets identified in papaya fruit. This table is a full version (edited in Excel program) of Table 1 with crude data (19,286 probe-sets) and treated data (414 probe-sets). It describes the principal characteristics of probe-sets retained after threshold cut-off and comparison between ripe $X$ unripe fruit, that includes systematic and common names of probe sets, normalized and raw values, fold time changes and $p$ values, as well as GO identities for biological process, molecular function and cellular component.
\end{abstract}

Additional file 3: Hierarchical clustering of ATH1-121501 probe-sets hybridized with papaya RNA. This figure describes the hierarchical clustering of the 414 probe-sets identified by the XSpecies microarray technique, showing different clusters of gene expression.

Additional file 4: Differentially expressed probe-sets identified in papaya fruit. This table is a shorter version of Additional file 2, also edited in Excel program. However this table shows the probe-sets collected for generation of GO plot figure by names (Figure 1A and B) and also describes the parameters of Genespring software from statistical analyses.

Additional file 5: Ripening analysis from three different samples of papaya fruit. This table describes the main parameters that were used for classifying as unripe (green) and ripe (yellow) papayas. This includes respiration ( $\mathrm{CO}_{2}$ production), ethylene production and pulp firmness.

Additional file 6: Differentially expressed probe-sets identified in papaya fruit. This table shows, in a reduced form, the probe-sets that were differentially expressed according to fold changes between ripe $X$ 
unripe, but with a statistical $p$-value cut-off of 0.10 , which returned 1,09 differentially expressed probe-sets.

Additional file 7: Overview of cell function transcripts from tomatoes, grapes and papayas in response to ripening. This figure describes the cell function transcripts from tomato, grape and papaya fruits when analysed with the MapMan software.These values (and identities) were the same used to structure the Venn diagram in Figure 2.

Additional file 8: Differentially expressed transcription factors from papaya, tomato and grape. This table is a simplified version of Table 2 (edited in Excel program) and Figure 3. The table only returns the results from MapMan analysis of overview ripening regulation of papaya fruit, but there is no comparison of transcription factors between three species.

Additional file 9: Nucleotide sequences used in qPCR. This table describes the primers used in Real Time-PCR analyses.

Additional file 10: Standard curve calculation of Real Time-PCR primers. This table describes the efficiency values, as well the standard curves for all primers used in Real Time-PCR experiments.

Additional file 11: Genbank ID and sequences of proteins used for comparative biology analyses. This is compacted (zipped) file which contains all sequences of proteins used for generating the phylogenetic trees in order to analyse the comparative biology between different.

\section{Abbreviations}

Blast: Basic Local Alignment Search Tool; GO: Gene Ontology; QPCR: quantitative PCR; PCR: Polymerase chain reaction; TF: Transcription factor; WGS: Whole genome shotgun; XSpecies Microarray: Cross Species Microarray.

\section{Competing interests}

The authors declare that they have no competing interests.

\section{Authors' contributions}

JPF wrote the article and performed the research. GBS and JRON corrected the manuscript and helped in its preparation. NSG, MRB and STM helped in data analysis and manuscript preparation. FML and BRC helped in manuscript preparation. All authors read and approved the final manuscript.

\section{Acknowledgements}

The authors thank the NASC team for helping with XSpecies hybridizations, Dr. Mervin Poole for assistance with the GPCR analyses and Caliman Agrícola S/A for providing fruits. The Fundação de Amparo à Pesquisa do Estado de São Paulo (FAPESP) supported this work through a grant (Project 02/124529) and scholarship to J.P.F. (03/00932-9 and 07/56515-8).

\section{Author details}

'University of São Paulo, Department of Food Science and Experimental Nutrition, FCF, São Paulo, Brazil. ${ }^{2}$ Plant and Crop Sciences Division, School of Biosciences, University of Nottingham, Sutton Bonington Campus, Loughborough, Leics LE12 5RD, UK. ${ }^{3}$ University of São Paulo, - NAPAN Food and Nutrition Research Center, São Paulo, Brazil.

Received: 10 July 2012 Accepted: 17 December 2012

Published: 21 December 2012

\section{References}

1. Fabi JP, Peroni FHG, Gomez MLPA: Papaya, mango and guava fruit metabolism during ripening: postharvest changes affecting tropical fruit nutritional content and quality. Fresh Produce 2010, 4:56-66.

2. Manenoi A, Bayogan ERV, Thumdee S, Paull RE: Utility of 1-methylcyclopropene as a papaya postharvest treatment. Post Biol Technol 2007, 44:55-62.

3. Fabi JP, Cordenunsi BR, Barreto GPM, Mercadante AZ, Lajolo FM, Nascimento JRO: Papaya fruit ripening: response to ethylene and 1-methylcyclopropene (1-MCP). J Agric Food Chem 2007, 55:6118-6123.

4. Moore S, Payton P, Wright M, Tanksley S, Giovannoni JJ: Utilization of tomato microarrays for comparative gene expression analysis in the Solanaceae. J Exp Botany 2005, 56:2885-2895.
5. Jiang $F$, Zheng $X$, Chen J: Microarray analysis of gene expression profile induced by the biocontrol yeast Cryptococcus laurentii in cherry tomato fruit. Gene 2009, 430:12-16.

6. Trainotti L, Tadiello A, Casadoro G: The involvement of auxin in the ripening of climacteric fruits comes of age: the hormone plays a role of its own and has an intense interplay with ethylene in ripening peaches. J Exp Bot 2007, 58:3299-3308.

7. Fabi JP, Lajolo FM, Nascimento JRO: Cloning and characterization of transcripts differentially expressed in the pulp of ripening papaya. Sci Hort 2009, 121:159-165.

8. Fabi JP, Mendes LRBC, Lajolo FM, Nascimento JRO: Transcript profiling of papaya fruit reveals differentially expressed genes associated with fruit ripening. Plant Sci 2010, 179:225-233.

9. Cin VD, Barbaro E, Danesin M, Velasco HMR, Ramina A: Fruitlet abscission: a CDNA-AFLP approach to study genes differentially expressed during shedding of immature fruits reveals the involvement of a putative auxin hydrogen symporter in apple (Malus domestica L. Borkh). Gene 2009, 442:26-36.

10. Ming R, Hou S, Feng $Y$, et al: The draft genome of the transgenic tropical fruit tree papaya (Carica papaya Linnaeus). Nature 2008, 452:991-997.

11. Hammond JP, Broadley MR, Craigon DJ, Higgins J, Emmerson Z, Townsend H, White PJ, May ST: Using genomic DNA-basedprobe-selection to improve the sensitivity of high-densityoligonucleotide arrays when applied to heterologous species. Plant Methods 2005, 9(1):10.

12. Bagnaresi P, Moschella A, Beretta O, Vitulli F, Ranalli P, Perata P: Heterologous microarray experiments allow the identification of the early events associated with potato tuber cold sweetening. BMC Genomics 2008, 9:176.

13. Thimm O, Blasing O, Gibon Y, Nagel A, Meyer S, Kruger P, Selbig J, Muller $L A$, Rhee SY, Stitt M: MAPMAN: a user-driven tool to display genomics data sets onto diagrams of metabolic pathways and other biological processes. Plant J 2004, 37:914-939.

14. Jamet E, Roujol D, San-Clement H, Irshad M, Soubigou-Taconnat L, Renou JP, Pont-Lezica R: Cell wall biogenesis of Arabidopsis thaliana elongating cells: transcriptomics complements proteomics. BMC Genomics 2009, 10:505.

15. Pilati S, Perazzolli M, Malossini A, Cestaro A, Demattè L, Fontana P, Dal Ri A, Viola R, Velasco R, Moser C: Genome-wide transcriptional analysis of grapevine berry ripening reveals a set of genes similarly modulated during three seasons and the occurrence of an oxidative burst at vèraison. BMC Genomics 2007, 8:428.

16. Ozaki S, Ogata Y, Suda K, Kurabayashi A, Suzuki T, Yamamoto N, lijima Y, Tsugane T, Fujii T, Konishi C, Inai S, Bunsupa S, Yamazaki M, Shibata D, Aoki K: Coexpression analysis of tomato genes and experimental verification of coordinated expression of genes found in a functionally enriched coexpression module. DNA Res 2010, 17:105-116.

17. Rodríguez-Concepción M: Supply of precursors for carotenoid biosynthesis in plants. Arch Bioch Biophysics 2010, 504:118-122

18. Allan $A C$, Roger $P H$, Laing WA: MYB transcription factors that colour our fruit. T Plant Sci 2008, 13:99-102.

19. Sharabi-Schwager M, Amnon Lers, Alon Samach, Charles L, Porat G: Overexpression of the CBF2 transcriptional activator in Arabidopsis delays leaf senescence and extends plant longevity. J Exp Botany 2010, 61:261-273.

20. Chung MY, Vrebalov V, Alba R, Lee J, McQuinn R, Chung JD, Klein P, Giovannoni J: A tomato (Solanum lycopersicum) APETALA2/ERF gene, $S I A P 2 a$, is a negative regulator of fruit ripening. Plant $J 2010$, 64:936-947

21. Karlova R, Rosin FM, Busscher-Lange J, Parapunova V, Do PT, Fernie AR Fraser PD, Baxter C, Angenent GC, de Maag RA: Transcriptome and metabolite profiling show that APETALA2a is a major regulator of tomato fruit ripening. Plant Cell 2011, 23:923-941.

22. Taken $\mathrm{E}$, Ireland $\mathrm{H}$, Gunaseelan $\mathrm{K}$, Karunairetnam S, Wang D, Schultz K, Bowen J, Atkinson RG, Johnston JW, Putterill J, Hellens RP, Schaffer RJ: The role of ethylene and cold temperature in the regulation of the apple POLYGALACTURONASE1 gene and fruit softening. Plant Physiol 2010, 153:294-305.

23. Li J, Dai X, Zhao Y: A role for auxin response factor 19 in auxin and ethylene signaling in Arabidopsis. Plant Physiol 2006, 140:899-908. 
24. De Jong M, Wolters-Arts M, Feron R, Mariani C, Vriezen WH: The Solanum lycopersicum auxin response factor 7 (SIARF7) regulates auxin signaling during tomato fruit set and development. Plant J 2009, 57:160-170.

25. Klee HJ, Giovannoni JJ: Genetics and control of tomato fruit ripening and quality attributes. Annu Rev Genetics 2011, 45:41-59.

26. Seymour GB, Ryder CD, Cevik V, Hammond JP, Popovich A, King GJ, Vrebalov J, Giovannoni JJ, Manning K: A SEPALLATA gene is involved in the development and ripening of strawberry (Fragaria $x$ ananassa duch.) fruit, a non-climacteric tissue. J Exp Botany 2011,

62:1179-1188.

27. Elitzur T, Vrebalov J, Giovannoni JJ, Goldschmidt EE, Friedman H: The regulation of MADS-box gene expression during ripening of banana and their regulatory interaction with ethylene. J Exp Botany 2010, 61:1523-1535.

28. Jaakola L, Poole M, Jones MO, Kämäräinen-Karppinen T, Koskimäki J J, Hohtola A, Häggman H, Fraser PD, Manning K, King GJ, Thomson H, Seymour GB: A SQUAMOSA MADS box gene involved in the regulation of anthocyanin accumulation in bilberry fruits. Plant Physiol 2010, 153:1619-1629.

29. Fabi JP, Cordenunsi BR, Seymour GB, Lajolo FM, Nascimento JRO: Molecular cloning and characterization of a ripening-induced polygalacturonase related to papaya fruit softening. Plant Physiol Biochem 2009, 47:1075-1081.

30. Soh CP, Ali ZM, Lazan H: Characterisation of a a-galactosidase with potential relevance to ripening related texture changes. Phytochem 2006, 67:242-254.

31. Nogueira SB, Labate CA, Gozzo FC, Pilau EJ, Lajolo FM, Nascimento JRO: Proteomic analysis of papaya fruit ripening using 2DE-DIGE. J Proteomics 2012, 75:1428-1439.

32. Marín-Rodríguez MC, Smith DL, Manning K, Orchard J, Seymour GB: Pectate lyase gene expression and enzyme activity in ripening banana fruit. Plant Mol Biol 2003, 51:851-857

33. Chourasia A, Sane VA, Nath P: Differential expression of pectate lyase during ethylene-induced postharvest softening of mango (Mangifera indica var. Dashehari). Physiol Plant 2006, 128:546-555.

34. Shiga TM, Fabi JP, Nascimento JRO, Petkowicz CLO, Vriesmann LC, Lajolo FM, Cordenunsi BR: Changes in cell wall composition associated to the softening of ripening papaya: evidence of extensive solubilisation of large molecular mass galactouronides. J Agric Food Chem 2009, 57:7064-7071.

35. Schroder R, Wegrzyn TF, Sharma NN, Atkinson RG: LeMAN4 Endo-betamannanase from ripe tomato fruit can act as a mannan transglycosylase or hydrolase. Planta 2006, 224:1091-1102

36. Opazo MC, Figueroa CR, Henríquez J, Herrera R, Bruno C, Valenzuela PD, Moya-León MA: Characterization of two divergent cDNAs encoding xyloglucan endotransglycosylase/hydrolase (XTH) expressed in fragaria chiloensis fruit. Plant Sci 2010, 179:479-488.

37. Gaete-Eastman C, Figueroa CR, Balbontína C, Moya M, Atkinson RG, Herrera R, Moya-León MA: Expression of an ethylene-related expansin gene during softening of mountain papaya fruit (Vasconcellea pubescens). Post Biol Technol 2009, 53:58-65.

38. Dotto MC, Matrínez GA, Civello PM: Expression of expansin genes in strawberry varieties with contrasting fruit firmness. Plant Physiol Biochem 2006, 44:301-307.

39. Hisawa K, Rose JKC, Nakano R, Inaba A, Kubo Y: Differential expression of seven a-expansin genes during growth and ripening of pear fruit. Physiol Plant 2003, 117:564-572.

40. Hayama H, Moriguchi Al, Kashimura Y: Identification of a new expansin gene closely associated with peach fruit softening. Post Biol Technol 2003, 29. $1 / 10$.

41. Kang JH, Wang L, Giri A, Baldwin IT: Silencing threonine deaminase and JAR4 in Nicotiana attenuata impairs jasmonic acid-isoleucine-mediated defenses against Manduca sexta. Plant Cell 2006, 18:3303-3320.

42. Li C, Schilmiller AL, Liu G, Lee Gl, Jayanty S, Sageman C, Vrebalov J, Giovannoni JJ, Yagi K, Kobayashi Y, Howe GA: Role of beta-oxidation in jasmonate biosynthesis and systemic wound signaling in tomato. Plant Cell 2005, 17:971-986.

43. Skirycz A, De Bodt S, Obata T, De Clercq I, Claeys H, De Rycke R, Andriankaja M, Van Aken O, Van Breusegem F, Fernie AR, Inze D: Developmental stage specificity and the role of mitochondrial metabolism in the response of
Arabidopsis leaves to prolonged mild osmotic stress. Plant Physiol 2010, 152:226-244.

44. Wang W, Vinocur B, Shoseyov O, Altman A: Role of plant heat-shock proteins and molecular chaperones in the abiotic stress response. Trends Plant Sci 2004, 9:244-252.

45. Faurobert M, Mihr C, Bertin N, Pawlowski T, Negroni L, Sommerer N, Causse M: Major proteome variations associated with cherry tomato pericarp development and ripening. Plant Physiol 2007, 143:1327-1346.

46. Manganaris GA, Rasori A, Bassi D, Geuna F, Ramina A, Tonutti P, Bonghi C: Comparative transcript profiling of apricot (Prunus armeniaca L.) fruit development and on-tree ripening. Tree Genetics Genomes 2011, 7:609-616.

47. Rotter A, Camps C, Lohse M, Kappel C, Pilati S, Hren M, Stitt M, CoutosThévenot P, Moser C, Usadel B, Delrot S, Gruden K: Gene expression profiling in susceptible interaction of grapevine with its fungal pathogen eutypa lata: extending MapMan ontology for grapevine. BMC Plant Biol 2009, 9:104

48. De Lorenzo G, D'Ovidio R, Cervone F: The role of polygalacturonaseinhibiting proteins (pgips) in defense against pathogenic fungi. Annu Rev Phytopathol 2001, 39:313-335.

49. Ioannidi E, Kalamaki MS, Engineer C, Pateraki I, Alexandrou D, Mellidou I, Giovannonni JJ, Kanellis AK: Expression profiling of ascorbic acid-related genes during tomato fruit development and ripening and in response to stress conditions. J Exp Botany 2009, 60:663-678.

50. Cruz-Rus E, Botella MA, Valpuesta V, Gomez-Jimenez MC: Analysis of genes involved in L-ascorbic acid biosynthesis during growth and ripening of grapeberries. J Plant Physiol 2010, 167:739-748.

51. Ali A, Muhammad MTM, Sijam K, Siddiqui Y: Effect of chitosan coatings on the physicochemical characteristics of eksotika II papaya (Carica papaya L.) fruit during cold storage. Food Chem 2011, 124:620-626.

52. Sambrook J, Fritsch EF, Maniatis T: Molecular Cloning: A Laboratory Manual. 3rd edition. Cold Spring Harbor, New York USA: Cold Spring Harbor Laboratory; 2000

53. The perl script was downloaded from The Nottingham Arabidopsis Stock Centre (NASC) website (http://arabidopsis.info/), specifically at the XSpecies section. (http://affymetrix.arabidopsis.info/xspecies/).

54. Irizarry RA, Hobbs B, Collin F, Beazer-Barclay YD, Antonellis KJ, Scherf U, Speed TP: Exploration, normalization, and summaries of high density oligonucleotide array probe level data. Biostatistics 2003, 4:249-264.

55. The software used for hierarchical clustering was accessed on line from Expression Profiler website. Analysis and clustering of gene expression and sequence data - available at http://www.bioinf.ebc.ee/EP/EP.

56. Usadel B, Nagel A, Steinhauser D, Gibon Y, Blaesing OE, Redestig H, Sreenivasulu N, Krall L, Hannah MA, Poree F, Fernie AR, Stitt M: PageMan an interactive ontology tool to generate, display, and annotate overview graphs for profiling experiments. BMC Bioinforma 2006, 7:535

57. Usadel B, Nagel A, Thimm O, Redestig H, Blaesing OE, Palacios-Rojas N, Selbig J, Hannemann J, Piques MC, Steinhauser D, Scheible WR, Gibon Y, Morcuende R, Weicht D, Meyer S, Stitt M: Extension of the visualization tool MapMan to allow statistical analysis of arrays, display of corresponding genes, and comparison with known responses. Plant Physiol 2005, 138:1195-1204

58. Expression data from Solanum lycopersicum cultivar MicroTom was downloaded from Tomato Functional Genomics Database website available at http://ted.bti.cornell.edu.

59. Expression data from Vitis vinifera cultivar Pinot Noir was downloaded from BMC website available at http://www.biomedcentral.com/1471-2164/8/428, referred to additional file 3 from reference 15 cited above (www. biomedcentral.com/content/supplementary/1471-2164-8-428-s3.xls).

60. Bustin SA, Benes V, Garson JA, Hellemans J, Huggett J, Kubista M, Mueller R, Nolan T, Pfaffl MW, Shipley GL, Vandesompele J, Wittwer CT: The MIQE guidelines: minimum information for publication of quantitative real-time PCR experiments. Clinical Chem 2009, 4:611-622.

61. Zuker M: Mfold web server for nucleic acid folding and hybridization prediction. Nucleic Acids Res 2003, 31:3406-3415. Program available at http://mfold.bioinfo.rpi.edu/cgi-bin/dna-form1.cgi.

62. Primers for Real Time-PCR experiments were designed using Primer 3 (v.0.4.0) tool available at http://fokker.wi.mit.edu/primer3/input.htm. 
63. Pfaffl MW: A new mathematical model for relative quantification in real-time RT-PCR. Nucleic Acids Res 2001, 29:2002-2007.

64. Thompson JD, Higgis DG, Gibson TJ: CLUSTALW: improving the sensitivity of progressive multiple sequence alignment through sequence weighting, position-specific gap penalties and weight matrix choice. Nucleic Acids Res 1994, 22:4673-4680.

65. Phylogenetic trees for comparative biology analysis were drawn using the Phylodendron@ software available at http://iubio.bio.indiana.edu/treeapp.

doi:10.1186/1471-2229-12-242

Cite this article as: Fabi et al:: Analysis of ripening-related gene expression in papaya using an Arabidopsis-based microarray. BMC Plant Biology 2012 12:242.

\section{Submit your next manuscript to BioMed Central and take full advantage of:}

- Convenient online submission

- Thorough peer review

- No space constraints or color figure charges

- Immediate publication on acceptance

- Inclusion in PubMed, CAS, Scopus and Google Scholar

- Research which is freely available for redistribution 